\title{
Blutiger Husten nach Verzehr von Krabbenfleisch
}

\author{
Eine Mahlzeit mit schlecht erhitzten Krustentieren hat mitunter unangenehme Folgen: \\ Egellarven können dabei über Magen und Darm in die Lunge wandern und blutigen Auswurf \\ verursachen, der an Tuberkulose erinnert.
}

Bei einem 18-jährigen Mann, der sich in einer Klinik in Kolumbien vorstellte, schien einiges auf eine Tuberkulose zu deuten: Er klagte seit einem Jahr über Husten, der immer wieder von blutigem Auswurf begleitet war, litt dabei aber nicht an Fieber. Das Röntgenbild zeigte multiple Knötchen und Zysten, was ebenfalls für eine Tuberkulose sprach. Allerdings fehlten die sonst üblichen TB-Symptome wie Gewichtsabnahme, allgemeine Schwäche und Nachtschweiß. Bis auf den Husten schien der Mann gesund zu sein. Auf die richtige Spur kamen die Ärzte um Dr. Marcos Arango Barrientos aus Medellin anhand der Blutuntersuchung: Sie ergab eine starke Eosinophilie mit über 3.000 eosinophilen Granulozyten pro Mikroliter - der Wert lag damit 10-fach über dem

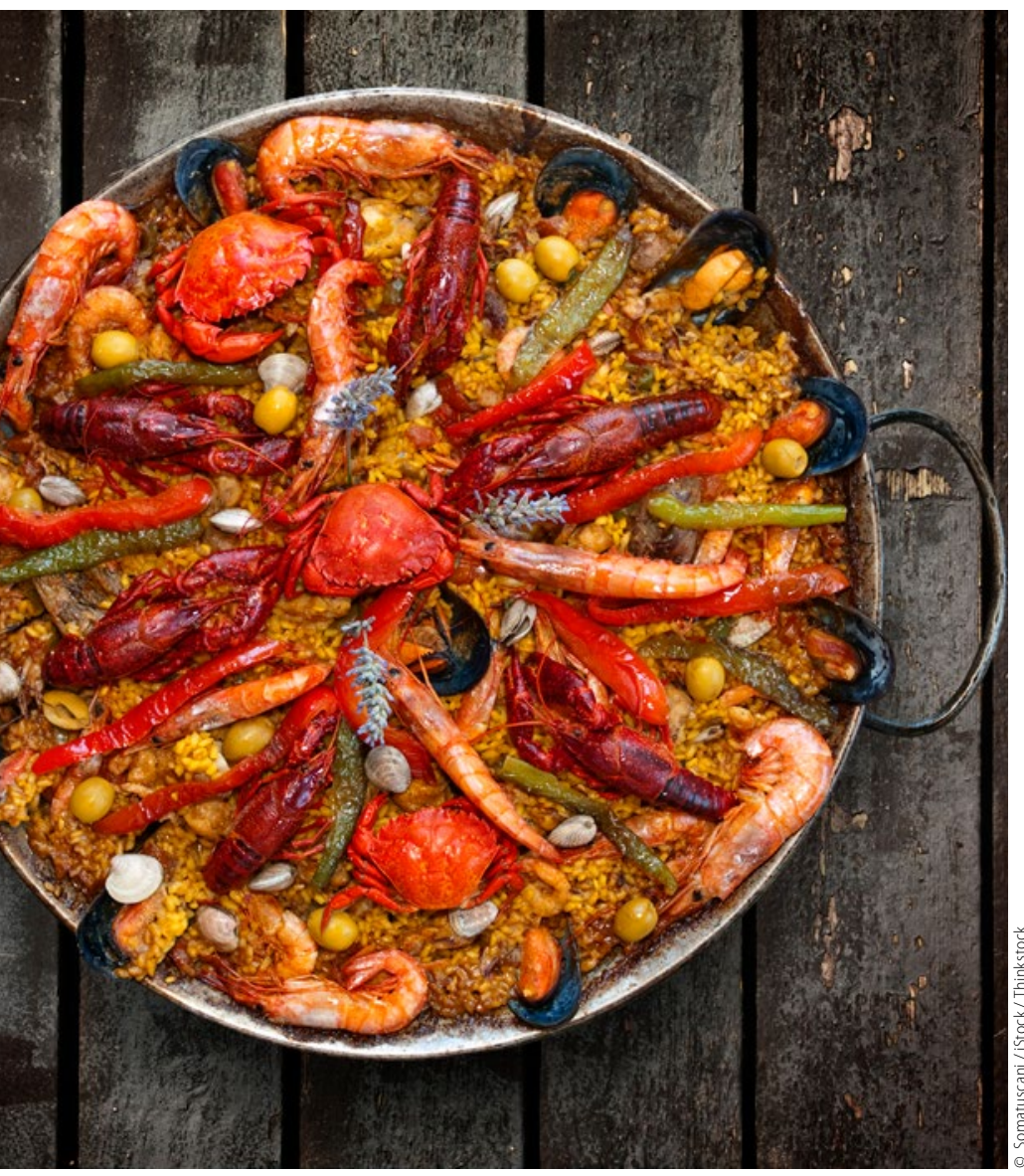

Riskante Mahlzeit: Schlecht erhitztes Krabbenfleisch beherbergen manchmal Egellarven, die die Lunge infizieren können.
Normbereich. Dieses Ergebnis sprach deutlich für eine Parasiteninfektion. Tatsächlich fanden die Ärzte bei einer bronchoalveolären Lavage Eier des Lungenegels Paragonimus.

\section{Larven wachsen in der Lunge zu Würmchen}

Hauptinfektionsquelle für den Egel sind schlecht erhitzte Flusskrebse oder andere Süßwasserkrustentiere. Sie enthalten mitunter Larven, die sich durch die Darmwand beißen, durchs Peritoneum bohren oder per Umweg über die Lebervene schließlich in die Lunge wandern, sich dort einkapseln und zu 8 bis 16 $\mathrm{mm}$ großen Tierchen heranwachsen. In regelmäßigen Abständen platzen die Lungenzysten - unzählige Eier werden dann über die Atemwege hochgehustet, verschluckt und über den Stuhl ausgeschieden. Zurück im Süßwasser schlüpfen daraus Larven, die sich nach neuen Zwischenwirten unter Schnecken, Krebsen und Krabben umschauen.

Die Krankheit zeigt sich am häufigsten als chronische Bronchitis. Zu Beginn der Infektion reagiert der Körper noch häufig mit Fieber, Schüttelfrost, Schweißausbrüchen sowie Magen- und Darmbeschwerden. Diese Symptome gehen nach einiger Zeit aber zurück und nach Monaten, manchmal auch erst nach Jahren, beginnt die chronische Phase mit periodischem Abhusten kleiner Blutmengen. Bei schweren Verläufen kann es dabei auch zu Nachtschweiß und Gewichtsabnahme kommen, was dann noch mehr als im vorgestellten Fall an eine Tuberkulose denken lässt. Die kleinen Würmchen fühlen sich bis zu 20 Jahre in der Lunge wohl, eine Therapie mit dem Antihelminthikum Praziquantel macht ihnen aber rasch den Garaus. Das Wurmmittel half auch dem 18-jährigen Kolumbianer: Nach 2 Monaten war er die Parasiten und den Husten los.

\section{Besser auf rohes Krabbenfleisch verzichten}

Generell wird empfohlen, nur gut erhitzte Krustentiere zu verspeisen und auf rohe Krabbenfleischspezialitäten, wie sie in einigen Ländern angeboten werden, zu verzichten. Urlauber sollten in exotischen Ländern zudem Süßwasserkrebse besser ganz meiden und sich allenfalls an gut gegarte Meerestiere halten, rät das Zentrum für Reisemedizin in Düsseldorf. Verbreitet ist der Lungenegel Paragonimus westermani allerdings weltweit. Geschätzt wird, dass etwa 3 Millionen Menschen damit infiziert sind. Einzelne Fälle von Lungen-Paragonimiasis wurden auch in den USA bei Süßwasserkrebs-Gourmets beobachtet.

Thomas Müller

Quelle: Barrientos MA et al. Images in Clinical Medicine: Paragonimiasis. N Engl J Med 2012;366:165 